\title{
Quantifying the Reactivity of a Remarkably Long-Lived Difluorinated Enol in Acidic Methanol via Solution Kinetics and Electronic Structure Calculations
}

\author{
Gerry A. Griffith, ${ }^{\S}$ Ian H. Hillier, ${ }^{*, \perp, \dagger}$ Jonathan M. Percy, ${ }^{*, l l, \ddagger}$ Ricard Roig, ${ }^{\S}$ and \\ Mark A. Vincent ${ }^{\perp}$ \\ Department of Chemistry, University of Leicester, University Road, Leicester LE1 7RH, United Kingdom, \\ School of Chemistry, University of Manchester, Oxford Road, Manchester M13 9PL, United Kingdom, and \\ Pure and Applied Chemistry, WestCHEM, University of Strathclyde, Thomas Graham Building, \\ 295 Cathedral Street, Glasgow G1 1XL, United Kingdom \\ jonathan.percy@strath.ac.uk
}

Received July 12, 2006

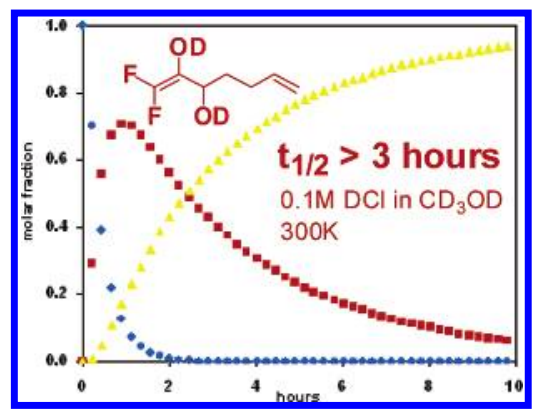

A simple enol acetal underwent rapid cleavage in acidic solution to generate a difluorinated enol, which was sufficiently long-lived to be characterized by 2D NMR in a protic solvent at ambient temperature. Density functional theory calculations on a model reaction suggest that there are significant differences in protonation transition state timing between the fluorinated and nonfluorinated enols.

\section{Introduction}

The relationship between enols and their aldehyde and ketone tautomers is one of the most fundamental in organic chemistry and a correct understanding of the phenomenon informs many ideas about reactions of profound synthetic importance, both in vivo and in vitro. The groundbreaking work of Capon, ${ }^{1}$ Kresge, $^{2}$ and Rappoport ${ }^{3}$ developed techniques for the generation and direct observation of enols, ynols, and other reactive intermediates which tautomerize to carbonyl compounds.

A major advance was made by Capon et al., ${ }^{4}$ who found that reactive ketene acetal $\mathbf{1}$ and ortho ester $\mathbf{2}$ hydrolyzed sufficiently rapidly for vinyl alcohol $\mathbf{3}$ to be observed in acetone-water

\footnotetext{
$\S$ University of Leicester.

${ }^{\perp}$ University of Manchester.

Corresponding author for computational chemistry.

" University of Strathclyde.

\# Corresponding author for synthetic chemistry and kinetics.

(1) Capon, B.; Guo, B. Z.; Kwok, F. C.; Siddhanta, A. K.; Zucco, C. Acc. Chem. Res. 1988, 21, 135.

(2) Kresge, A. J. Chem. Soc. Rev. 1996, 25, 275.

(3) Rappoport, Z.; Frey, J.; Sigalov, M.; Rochlin, E. Pure Appl. Chem. 1997, 69, 1933.
}

(99:1). Relatively long-lived solutions of $\mathbf{3}$ (for example $t_{1 / 2} \mathrm{ca}$. $10 \mathrm{~min}, \mathrm{MeCN}, 293 \mathrm{~K}$ ) could be prepared by manipulating reaction conditions subtly. Kresge developed the laser flash photolysis technique ${ }^{5}$ to allow the direct study of a wider range of reactive intermediates in water and to reveal structure reactivity relationships. For example, enols $\mathbf{4}$ and $\mathbf{5}$ are ca. $10^{2}$ times $\left(t_{1 / 2}\right.$ ca. $\left.0.5 \mathrm{~s}\right)$ and 4 times $\left(t_{1 / 2} \mathrm{ca} .10 \mathrm{~s}\right)$ more reactive than $3\left(t_{1 / 2}\right.$ ca. $35-45 \mathrm{~s}$ between $\mathrm{pH} 3.5$ and 5.0), respectively.

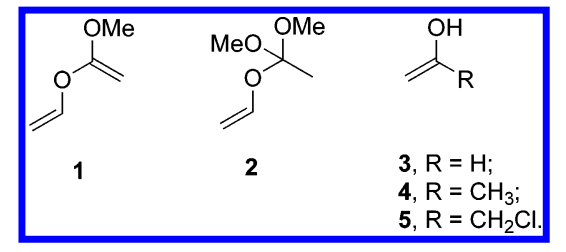

Keto/enol tautomerism of aldehydes,${ }^{6}$ acids, ${ }^{7}$ and dicarbonyl compounds ${ }^{8}$ has been studied by computational chemists. Most

(4) (a) Capon, B.; Rycroft, D. S.; Watson, T. W.; Zucco, C. J. Am. Chem. Soc. 1981, 103, 1761. (b) Capon, B.; Zucco, C. J. Am. Chem. Soc. 1982, 104, 7567.

10.1021/jo061450y CCC: $\$ 33.50$ @ 2006 American Chemical Society Published on Web 09/22/2006 
studies concentrate on the relative gas-phase energies of enol and ketone forms; the interconversion between keto and enol forms in solution and the modeling of transition states is less well explored. Dickerson and co-workers, ${ }^{9}$ and more recently, Houk and Zhang, ${ }^{10}$ studied the aldol reaction in pure water. In the latter study, the self-condensation of acetaldehyde was explained via the enol, itself formed via a facile general base and general acid catalyzed reaction, rather that via an enolate. The calculations also showed that the autoionization of water is responsible for the presence of the catalytic hydroxide and hydronium ions.

Steric and electronic effects have been enlisted to produce enols with extended lifetimes; ${ }^{11}$ the presence of electron withdrawing substituents can extend the lifetime of enols dramatically. For example, Knunyants and co-workers ${ }^{12}$ described how 6 could be stored indefinitely and distilled without significant tautomerization to the corresponding ketone 7. More recently, Burger prepared $\mathbf{8}$, and noted that it was stable under acidic conditions. ${ }^{13}$

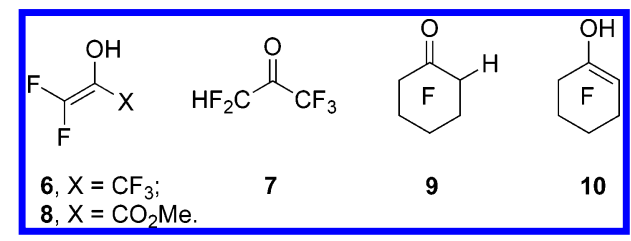

Lemal and co-workers have also shown that perfluorination can shift the thermodynamic balance in the keto/enol tautomeric equilibrium under aprotic conditions; ${ }^{14}$ Lewis basic solvents favor the enol form of general type $\mathbf{1 0}$ by hydrogen bond formation to the enol hydroxyl group, and by strong destabilization of the keto-form 9 . The $-\mathrm{CO}_{2} \mathrm{Me}$ and perfluoroalkyl groups are powerfully electron withdrawing (inductively $(-I)$ in both cases, through resonance $(-R)$ in the former additionally) and their effects can be understood qualitatively by referring to the accepted ketonization mechanism in which general acid cata-

(5) (a) Chiang, Y.; Hojatti, M.; Keeffe, J. R.; Kresge, A. J.; Schepp, N. P.; Wirz, J. J. Am. Chem. Soc. 1987, 109, 4000. (b) For a review, see: Kresge, A. J.Acc. Chem. Res. 1990, 23, 43. (c) For a recent example, see: Chiang, Y.; Kresge, A. J.; Onyido, I.; Richard, J. P.; Wan, P.; Xu, M. Chem. Commun. 2005, 4231.

(6) (a) Heinrich, N.; Koch, W.; Frenking, G.; Schwarz, H. J. Am. Chem. Soc. 1986, 108, 593. (b) Lee, D.; Kim, C. K.; Lee, B. S.; Lee, I.; Lee, B. C. J. Comput. Chem. 1997, 18, 56. (c) Suenobu, K.; Nagaoka, M.; Yamabe, T. J. Mol. Struct. (THEOCHEM) 1999, 461, 581. (d) Chuang, C. H.; Lien, M. H. Eur. J. Org. Chem. 2004, 1432.

(7) (a) Sklenák, S.; Apielog, Y.; Rappoport, Z. J. Am. Chem. Soc. 1998 , 120, 10359. (b) Rosenberg, R. E. J. Org. Chem. 1998, 63, 5562. (c) Allen, A. D.; Fedorov, A. V.; Tidwell, T. T.; Vukovic, S. J. Am. Chem. Soc. 2004, 126, 15777.

(8) (a) Hoz, S.; Kresge, A. J. J. Phys. Org. Chem. 1997, 10, 182. (b) Yamabe, S.; Tsuchida, N.; Miyajima, K. J. Phys. Chem. A 2004, 108, 2750. (c) Paine, S. W.; Kresge, A. J.; Salam, A. J. Phys. Chem. A 2005, 109, 4149.

(9) Dickerson, T. J.; Lovell, T.; Meijler, M. M.; Noodleman, L.; Janda, K. D. J. Org. Chem. 2004, 69, 6603.

(10) Zhang, X.; Houk, K. N. J. Org. Chem. 2005, 70, 9712.

(11) For a review and a wide ranging discussion of simple enols, see: Rappoport, Z. The Chemistry of Enols; Wiley-Interscience: New York, 1990.

(12) Bekker, R. A.; Melikyan, G. G.; Dyatkin, B. L.; Knunyants, I. L. Zh. Org. Khim. 1975, 1370; English (Plenum) 1975, 1356.

(13) Osipov, S. N.; Golubev, A.; Sewald, N.; Kolomiets, A. F.; Fokin, A. V.; Burger, K. Synlett 1995, 1269.

(14) (a) Lindner, P. E.; Lemal, D. M. J. Am. Chem. Soc. 1997, 119, 3259. (b) Lindner, P. E.; Lemal, D. M. J. Org. Chem. 1996, 61, 5109. (c) Lindner, P. E.; Correa, R. A.; Gino, J.; Lemal, D. M. J. Am. Chem. Soc. 1996, 118, 2556.
SCHEME 1. Synthesis of Dioxolane 13

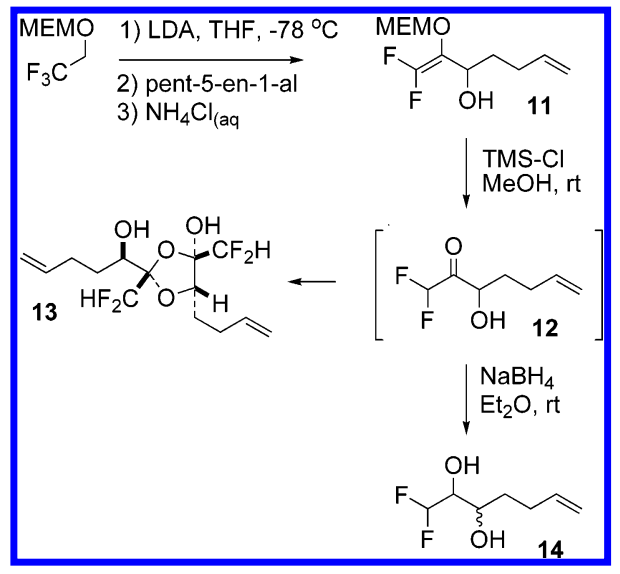

lyzed protonation at carbon leads to oxacarbenium ion formation, followed by proton loss from oxygen to afford the neutral carbonyl species. Enols 6, 8, and $\mathbf{1 0}$ contain a $-I$ substituent at every available position, so the difficulty of positive charge development is reasonable. The alternative ketonization mechanism involves ionization of enol to enolate followed by protonation by any available acid. ${ }^{15}$ The $\mathrm{p} K_{\mathrm{a}}^{\mathrm{E}}$ values (which measure the oxygen acidities of enols) are unknown for fluorinated enols but Lemal discovered ${ }^{14 a}$ that a perfluoroenol was a stronger hydrogen bond donor than hexafluoro-2-propanol so fluorination should lower $\mathrm{p} K_{\mathrm{a}}^{\mathrm{E}}$, meaning that the enolate becomes available at higher acid concentrations. None of these studies allow us to predict quantitatively how a simple difluorinated enol will behave under protic conditions, or indeed if such species can be seen at all. We wish to characterize such a species in this paper, and show via density functional calculations that its kinetic metastability arises from strong destabilization of the transition state for protonation at carbon.

\section{Results and Discussion}

During the course of a synthetic campaign, we wished to cleave difluoroallylic alcohol 11 to hydroxyketone $\mathbf{1 2}$ and reduce in situ to diol 14 (Scheme 1). Exposure of $\mathbf{1 1}$ to acidic methanol, conditions we had developed successfully for the cleavage of MEM ((methoxy)ethoxymethyl) enol acetals ${ }^{16}$ returned crude product with a complex ${ }^{19} \mathrm{~F}$ NMR spectrum, and ultimately a crystalline solid, identified as dioxolane dimer 13 by X-ray crystallographic analysis.

We were curious about the timing of dimerization of $\mathbf{1 2}$, so we followed the methanolysis of $\mathbf{1 1}$ (in $\mathrm{CD}_{3} \mathrm{OD} / \mathrm{Me} \mathrm{SiCl}_{3}$ ) by ${ }^{19} \mathrm{~F}$ NMR, observing complete consumption of the starting material and the buildup of a difluoroalkenyl intermediate (either 15 or 16, clearly visible in the ${ }^{19} \mathrm{~F}$ and ${ }^{13} \mathrm{C}$ NMR spectra), which decayed to $\mathbf{1 3}$ on a longer time scale.

Scheme 2 shows the expected mechanism for cleavage of the MEM enol acetal; the spectra indicated unambiguously that protonation at carbon cannot be the initial step, but they failed to distinguish between $\mathbf{1 5}$ and $\mathbf{1 6 .}$

The critical feature distinguishing $\mathbf{1 5}$ and $\mathbf{1 6}$ is the connection between the enolic oxygen and the acetal carbon $\mathrm{C}-1^{\prime}$, present

(15) Keefe, J. R.; Kresge, A. J. In The Chemistry of Enols; Rappoport, Z., Ed.; Wiley, New York, 1990; Chapter 7.

(16) (a) Cox, L. R.; DeBoos, G. A.; Fullbrook, J. J.; Percy, J. M.; Spencer, N. S.; Tolley, M. Org. Lett. 2003, 5, 337. (b) Broadhurst, M. J.; Brown, S. J.; Percy, J. M.; Prime, M. E. J. Chem. Soc. Perkin Trans. 1 2000, 3217. 


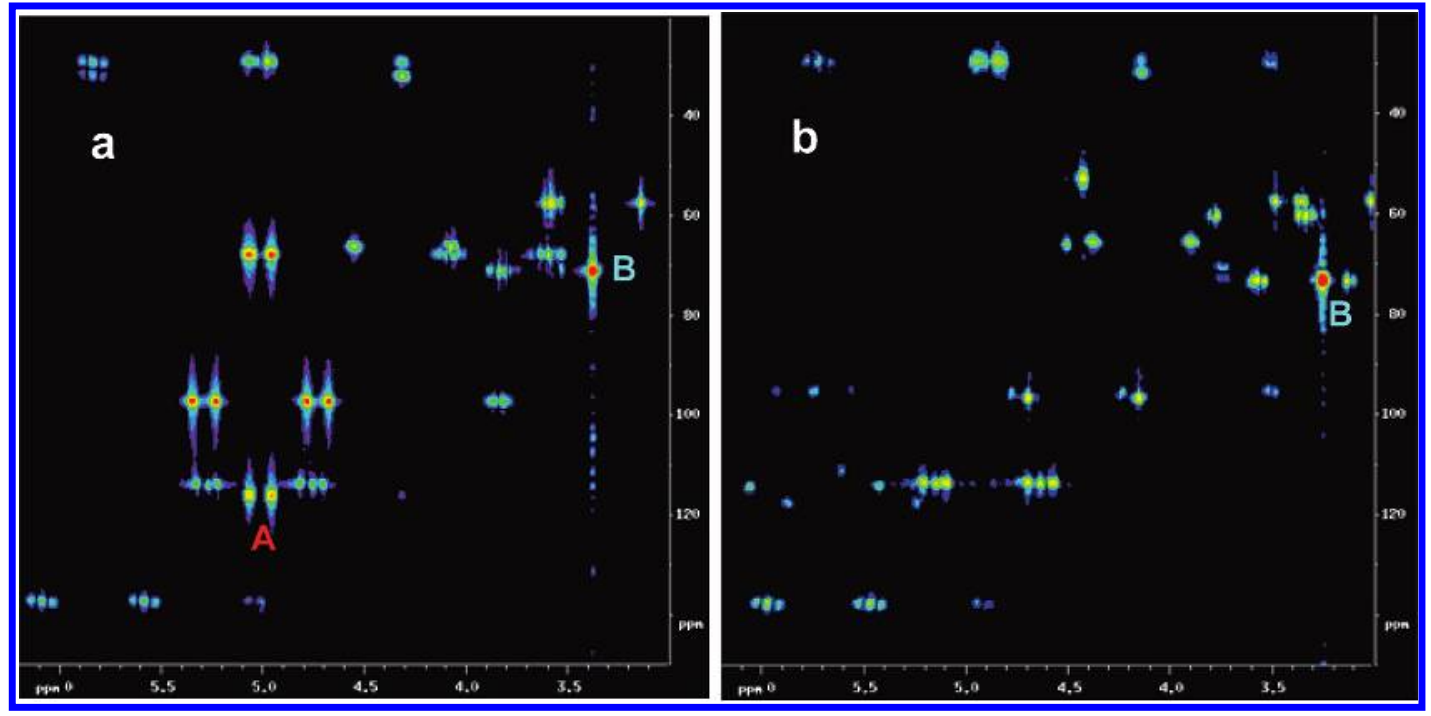

FIGURE 1. Partial HMBC spectra of $11\left({ }^{1} \mathrm{H} 400 \mathrm{MHz}, \mathrm{CD}_{3} \mathrm{OD}, 300 \mathrm{~K}\right)$ : (a) 11 alone; (b) 100 min after the addition of TMS-Cl to $0.01 \mathrm{M}$. The two spectra were normalized to the same contour level, using peak B.

\section{SCHEME 2. Mechanism for Cleavage of the Enol Acetal}

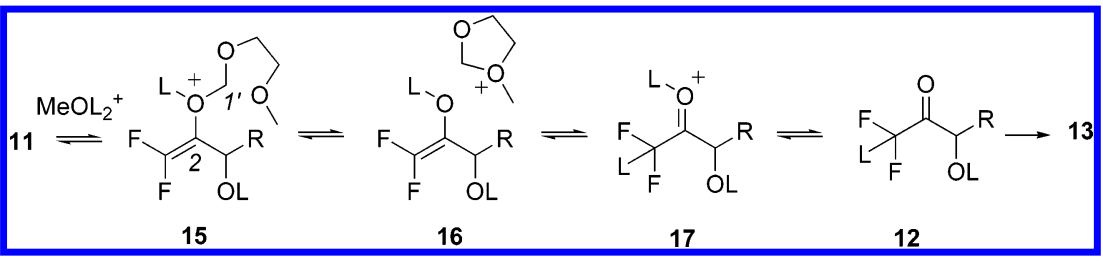

in the former and cleaved in the latter. Instead, we propose that deuteriation occurs at the enolic oxygen of $\mathbf{1 1}$ to afford $\mathbf{1 5}$ followed by $\mathrm{C}-\mathrm{O}$ bond cleavage to release the difluoroenol 16, ${ }^{17}$ which then undergoes rate-limiting deuteriation at carbon in the acidic medium to release $\mathbf{1 7}$.

At the start of the reaction, the fully assigned heteronuclear multiple bond correlation (HMBC) spectrum of $\mathbf{1 1}$ shows a clear cross-peak $\left(\mathrm{A},{ }^{3} J_{\mathrm{C}-\mathrm{H}}\right)$ connecting $\mathrm{C}-2$ and the diastereotopic $\mathrm{H}-1^{\prime}$ methylene protons (Figure 1a). At $50 \%$ consumption of 11, a new $\mathrm{C}-2$ type carbon is clearly visible in the ${ }^{13} \mathrm{C}$ NMR spectrum, then later in the reaction, when $\mathbf{1 1}$ has been consumed completely, the HMBC spectrum (Figure 1b) shows that there is no connection between the new $\mathrm{C}-2$ carbon and the acetal methylene, consistent only with cleavage of the key $\mathrm{C}-\mathrm{O}$ bond and enol formation.

Solutions of $16(\mathrm{~L}=\mathrm{D})$ could be generated by dissolving 11 in $\mathrm{CD}_{3} \mathrm{OD}$ without adding any acid; for example, after 13 days, a solution of $\mathbf{1 1}$ in $\mathrm{CD}_{3} \mathrm{OD}$ had converted completely to 16 with only trace amounts of ketonic products visible (see the Supporting Information). Presumably this reaction arises from the presence of traces of acid in the synthetic product causing cleavage of the MEM group upon storage. This corresponds to a half-life of much greater than 2 weeks at very low acid concentration $\left(k_{\mathrm{o}}<5 \times 10^{-7} \mathrm{~s}^{-1}\right)$. Enol formation from the enol acetal is much faster at any given acid concentration than ketonization so intermediate buildup is reasonable when the concentration of acid is very low. The measured half-life of $\mathbf{1 6}$ in $\mathrm{CD}_{3} \mathrm{OD}(0.1 \mathrm{M}$ in DCl, $300 \mathrm{~K})$ is $1.19 \times 10^{4} \mathrm{~s}$ or $3.3 \mathrm{~h} ; k_{\mathrm{D}}{ }^{+}$ $=4.76 \times 10^{-4} \mathrm{M}^{-1} \mathrm{~s}^{-1}$ and $k_{\mathrm{H}}^{+}=1.94 \times 10^{-3} \mathrm{M}^{-1} \mathrm{~s}^{-1}$

(17) Vinyl acetals are known to undergo intial acetal hydrolysis to release the enol, followed by ketonization; see: Chiang, Y.; Chwang, W. K.; Kresge, A. J.; Yin, Y. J. Am. Chem. Soc. 1989, 111, 7185. correspond to a solvent kinetic isotope effect of 4.07, which compares well with literature values of 4.61 and 2.98 for vinyl alcohol and ethyl vinyl ether protonation respectively in water. ${ }^{5}$ The absolute reactivity cannot be assessed from current data; $k_{\mathrm{H}}{ }^{+}$for acetone enol is $4.7 \times 10^{3} \mathrm{M}^{-1} \mathrm{~s}^{-1}$ at $298 \mathrm{~K}$ in water (a difference of $10^{6}$ ) but the effect of transferring enol protonation reactions from water to alcohol solvents appears to be unknown.

To understand the reasons for the stability of the difluoroenol 16, we have modeled the keto-enol interconversion of difluorovinyl alcohol $\mathbf{1 8}$ and vinyl alcohol itself $\mathbf{3}$, in liquid methanol

$$
\mathrm{F}_{\mathrm{F}}^{\mathrm{OH}} 18
$$

containing $\mathrm{HCl}$. If such a keto-enol interconversion proceeded via an intramolecular mechanism (1,3-shift), a highly strained cyclic transition structure of high energy would be involved. Houk and Zhang ${ }^{10}$ have calculated activation barriers of 293 $\mathrm{kJ} \mathrm{mol}^{-1}$ for the direct 1,3-shift and $173 \mathrm{~kJ} \mathrm{~mol}^{-1}$ for catalysis via a single explicit water molecule; neither mechanism is therefore likely. In a protic solvent a more favorable mechanism involves proton shuttling in which keto-enol interconversion proceeds by one protonated solvent molecule donating a proton to the solute, and a second neutral solvent molecule receiving a proton from the solute. There will naturally be many possible solvent-solute configurations which will allow such a reaction to occur. Our strategy is to construct a credible structure for a cluster consisting of a number of methanol molecules, one of which is protonated, a chloride counterion, and the keto or enol solute. We then determine the reactant, product, and transition structures using a density functional theory (DFT) method. The effect of the bulk solvent on the relative free energies of these 


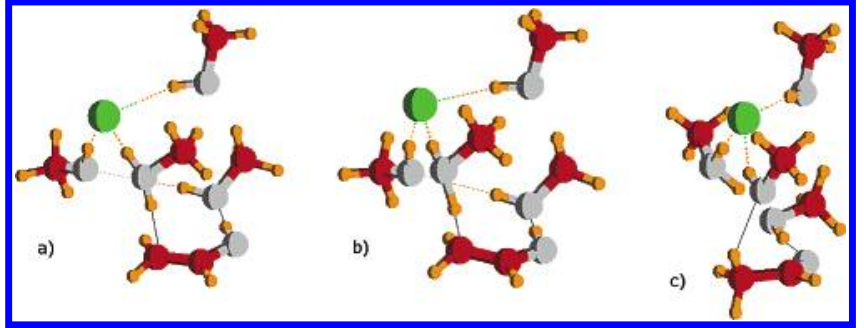

FIGURE 2. Stationary structures for enol-keto conversion: (a) enol reactant; (b) protonation transition structure; and (c) ketonic product. See Figure 3 for bond lengths.

structures is estimated by using the polarizable continuum model (PCM). The DFT calculations were carried out with the B3LYP functional (as implemented in Gaussian98 ${ }^{18}$ ) together with a large Gaussian basis $\left(6-311++\mathrm{G}^{* *}\right)$, having the necessary diffuse functions to correctly describe anions.

A recent Car-Parrinello molecular dynamics simulation of $\mathrm{Li}^{+}$and $\mathrm{Cl}^{-}$ions in liquid methanol ${ }^{19}$ has given an average coordination number of 3.56 for the chloride anion. We thus started with a cluster in which the $\mathrm{Cl}^{-}$was solvated by four methanol molecules, one of which was protonated. Vinyl alcohol 3 was then placed such that its $\pi$-electron density hydrogen bonded to one of the hydrogens $(\mathrm{OH})$ of the protonated methanol, and the transition structure for the enol-keto transformation of $\mathbf{3}$ via an intermolecular proton shuttle route was determined. This search for the transition structure resulted in some reorganization of the starting structure to give one in which three methanol molecules were coordinated to the chloride anion, and the fourth, which is the proton acceptor, is itself hydrogen bonded to a second methanol molecule. Such a threecoordinate structure is entirely compatible with the results of MD simulations. ${ }^{20}$ This generic transition structure is shown in Figure $2 \mathrm{~b}$

The reaction was followed from this transition structure to give the reactant and product structures shown in Figure 2a,c. All three stationary structures were properly characterized by calculation of their harmonic frequencies. In both reactant and product, the chloride anion remained three coordinate.

The calculation for the keto-enol conversion of difluorovinyl alcohol $\mathbf{1 8}$ was carried out starting from a transition structure similar to that for vinyl alcohol itself. Selected bond lengths and charges, together with reaction free energies and barriers for the two reactions are summarized in Figure 3.

There are considerable differences between the transition structures for the two reactions. The transition structure for the

(18) Frisch, M. J.; Trucks, G. W.; Schlegel, H. B.; Scuseria, G. E.; Robb, M. A.; Cheeseman, J. R.; Zakrzewski, V. G.; Montgomery, J. A., Jr.; Stratmann, R. E.; Burant, J. C.; Dapprich, S.; Millam, J. M.; Daniels, A. D.; Kudin, K. N.; Strain, M. C.; Farkas, O.; Tomasi, J.; Barone, V.; Cossi, M.; Cammi, R.; Mennucci, B.; Pomelli, C.; Adamo, C.; Clifford, S.; Ochterski, J.; Petersson, G. A.; Ayala, P. Y.; Cui, Q.; Morokuma, K.; Malick, D. K.; Rabuck, A. D.; Raghavachari, K.; Foresman, J. B.; Cioslowski, J.; Ortiz, J. V.; Baboul, A. G.; Stefanov, B. B.; Liu, G.; Liashenko, A.; Piskorz, P.; Komaromi, I.; Gomperts, R.; Martin, R. L.; Fox, D. J.; Keith, T.; AlLaham, M. A.; Peng, C. Y.; Nanayakkara, A.; Gonzalez, C.; Challacombe, M.; Gill, P. M. W.; Johnson, B.; Chen, W.; Wong, M. W.; Andres, J. L.; Head-Gordon, M.; Replogle, E. S.; Pople, J. A. Gaussian 98; Gaussian, Inc.: Pittsburgh, PA, 1998

(19) Pagliai, M.; Cardini, G.; Schettino, V. J. Phvs. Chem. B 2005, 109 7475.

(20) Tidwell has recently described a transition structure in which six water molecules link the $\alpha$-carbon to an intramolecular basic group: Fedorov, A. V.; Najafian, K.; Tidwell, T. T.; Vukovic, S. Can. J. Chem. 2005, 83,1561 .

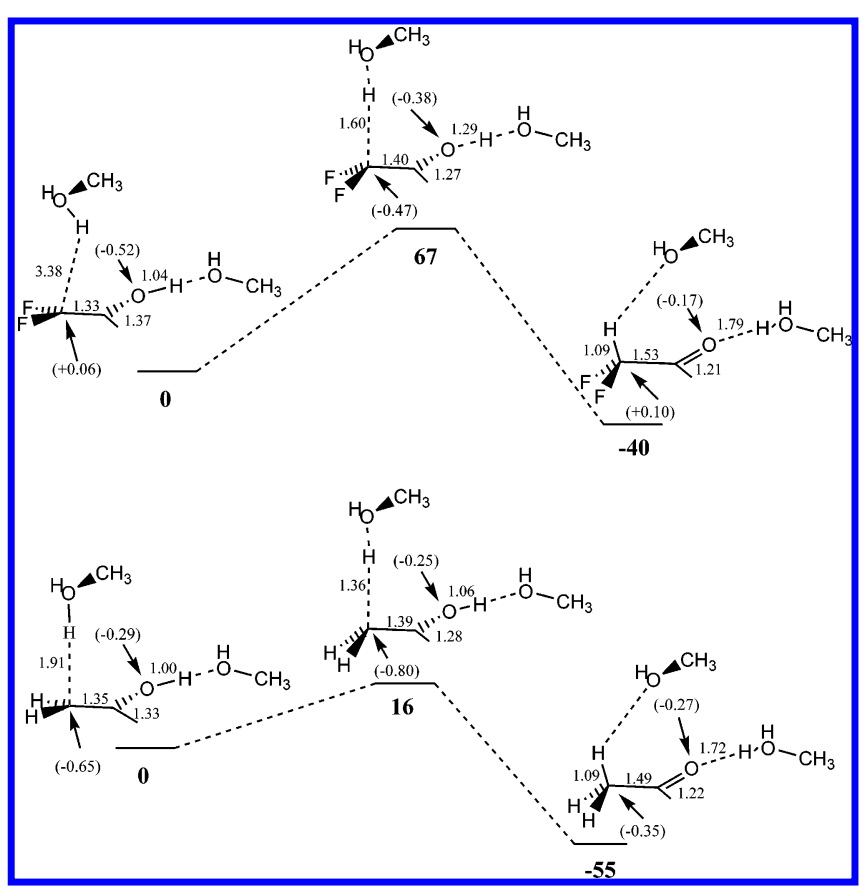

FIGURE 3. Bond lengths $(\AA)$, free energies (in bold, $\mathrm{kJ} \mathrm{mol}^{-1}$ ) relative to reactant at $298 \mathrm{~K}$, and atomic charges (in parentheses) for enol reactant, ketonic product, and transition structure for protonation.

tautomerization of vinyl alcohol $\mathbf{3}$ involves very little $\mathrm{O}-\mathrm{H}$ bond breaking and significant $\mathrm{C}-\mathrm{H}$ bond formation, while the situation is very different for the difluoro analogue 18. Here there is considerable $\mathrm{O}-\mathrm{H}$ bond lengthening and a much lower degree of $\mathrm{C}-\mathrm{H}$ bond formation in the transition structure. This correlates with the considerable increase in the electron density, compared to the vinyl alcohol case, which must take place on the carbon that is accepting the proton, before such atom transfer can occur. The inductive effects of the fluorine atoms would of course be expected to acidify the $\mathrm{OH}$ in $\mathbf{1 6}$ and $\mathbf{1 8}$. There is also more $\mathrm{C}-\mathrm{C}$ bond lengthening and $\mathrm{C}-\mathrm{O}$ bond shortening in the transition structure for 18, which again reflects that $\mathrm{O}-\mathrm{H}$ bond breaking is well advanced. Indeed, the transition structure for $\mathbf{1 8}$ more closely resembles one for enolate protonation at carbon via a hydrogen-bonded carbanion.

Both enol to keto tranformations are favored energetically, that for vinyl alcohol being the more exergonic by $15 \mathrm{~kJ} \mathrm{~mol}^{-1}$, consistent with some destabilization of the ketone by the two fluorine atoms. ${ }^{14 a}$ However, the considerable differences in the transition structures for the two reactions led to a much larger barrier for the difluoro species $18\left(67 \mathrm{~kJ} \mathrm{~mol}^{-1}\right)$, compared to vinyl alcohol $\left(16 \mathrm{~kJ} \mathrm{~mol}^{-1}\right)$. Both the reaction free energies and barriers are little affected by the inclusion of the bulk solvent at the PCM level. We were pleased to note that despite the entropic penalty associated with the recruitment of four molecules of solvent to the cluster, the barrier calculated for the protonation of $\mathbf{3}$ is considerably lower that those calculated by Houk and Zhang ${ }^{10}$ for the 1,3-shift and water-catalyzed enolizations of acetaldehyde.

We may estimate the relative reaction rates of $\mathbf{3 : 1 8}$ from our free energy barriers. The resulting value, $8 \times 10^{8}: 1$, is in semiquantitative agreement with our experimental estimate of $10^{6}$. We have also estimated the deuterium kinetic isotope values for the two reactions within the rigid-rotor, harmonic oscillator approximation, giving values of 5.1 for the difluoro species $\mathbf{1 8}$ and 3.7 for vinyl alcohol 3. The experimental sKIE for $16(\mathrm{~L}$ 


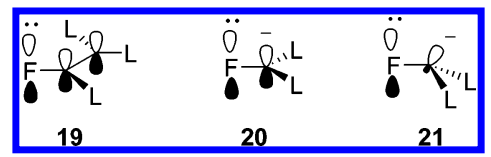

FIGURE 4. Orbital representations of fluorine atom $\mathrm{p}-\pi$ repulsion.

= D) was 4.07 in methanol, while the measured value in water for 3 was 4.61. These experimental values suggest that proton tunneling is not an important contributor to the reaction rate. This is born out by the lack of a particularly narrow barrier for both reactions, with the imaginary frequencies of -917 and $-611 \mathrm{~cm}^{-1}$ for 3 and $\mathbf{1 8}$, respectively, being not unduly large. The agreement between the measured and calculated values for the difluorinated enols in methanol is reasonable given the somewhat simplified model we have used, and lends support to the proton shuttle mechanism we have proposed. The values for 3 were obtained in different solvents so comparison is difficult, especially considering the very different transition structures traversed by the two enols.

That the two fluorine atoms would oppose protonation was expected, but the change in the transition structure for protonation was more of a surprise. Fluorine atoms destabilize alkenes to which they are attached (Figure 4). ${ }^{21}$

The fluorine lone pairs are the cause of $p-\pi$ repulsions (in 19 and 20), which can be relieved by pyramidalization of carbanion centers that bear them (in 21), reducing the degree of repulsive overlap. Pyramidalization also reduces the stabilizing effects of carbonyl groups on carbanions through delocalization for the same reason..$^{22}$ Hine and co-workers ${ }^{23}$ made the original observations in this area, noting that the rate of isotopic exchange into the acidic position was lower than predicted by the Taft equation in fluoro- and methoxyacetates (the same effect also applies in the latter case). Castejon and Wiberg have carried out MP2 calculations which confirm this rationalization and support the idea that fluorine atoms acidify species which form pyramidal ions. ${ }^{24}$ Bickelhaupt, Boche, and co-workers have shown that fluorine is more effective than the heavier halogens in this role. ${ }^{25}$ The reorganization observed for $\mathbf{1 8}$ is minimizing the development of positive charge (which would be very strongly destabilized by the fluorine atoms) by re-timing the proton transfer and developing enolate character. The high acidity of the enol hydroxyl group should facilitate this reorganization; pyramidalization then minimizes destablization by the fluorine atoms. Nevertheless, the barrier and resulting kinetic stabilization of the enol remains considerable.

We believe that the longevity of $\mathbf{1 6}$ is remarkable given the absence of additional electron withdrawing groups, and now wish to explore the ability of a pair of small, electronegative fluorine atoms to extend enol lifetime in biologically useful situations. $^{26}$

(21) For a description of this effect of this destabilization on rearrangement reactions: Black, K. A.; Wilsey, S.; Houk, K. N. J. Am. Chem. Soc. 2003, 125, 6715 . 2006.

(22) Uneyama, K. Organofluorine Chemistry: Blackwell: Oxford, UK,

(23) (a) Hine, J.; Mahone, L. G.; Liotta, C. L. J. Am. Chem. Soc. 1967, 89, 5911. (b) For a recent description of this effect during the enolization of hydroxyacetone, see: Crugieras, J.; Richard, J. P. J. Am. Chem. Soc. 2004, 126, 5164. (c) For a computational study of the deprotonation of fluoroacetyl SCoA by citrate synthase, see: Yang, W.; Drueckhammer, D. G. J. Phvs. Chem. B 2003, 107, 5986.

(24) Castejon, H. J.; Wiberg, K. B. J. Org. Chem. 1998, 63, 3937.

(25) Bickelhaupt, F. M.; Hermann, H. L.; Boche, G. Angew. Chem., Int. Ed. 2006, 45, 823 .

\section{Experimental Section}

1,1-Difluoro-2-(2-methoxyethoxymethoxy)hepta-1,6-diene-3ol (11). $n$-Butyllithium ( $75 \mathrm{mmol}, 32 \mathrm{~mL}$ of $2.40 \mathrm{M}$ solution in hexane) was added dropwise to a cold $\left(-78{ }^{\circ} \mathrm{C}\right)$ solution of diisopropylamine $(78 \mathrm{mmol}, 9.8 \mathrm{~mL})$ in dry THF $(36 \mathrm{~mL})$ under nitrogen. The solution was allowed to warm to $-30{ }^{\circ} \mathrm{C}$ and then cooled again to $-78{ }^{\circ} \mathrm{C}$. 2-(Methoxyethoxymethoxy)-1,1,1-trifluoroethane $^{27}$ (36 mmol, $6.6 \mathrm{~g}$ ) was added dropwise over $30 \mathrm{~min}$ to this freshly made LDA solution. The reaction was stirred at this temperature for $40 \mathrm{~min}$, then 5-penten-1-al (42 mmol, $3.6 \mathrm{~g}$ ) was added in one portion. The mixture was allowed to warm to -30 ${ }^{\circ} \mathrm{C}$ over $2 \mathrm{~h}$, then quenched with $\mathrm{NH}_{4} \mathrm{Cl}(30 \mathrm{~mL}$ of a saturated aqueous solution). Water $(30 \mathrm{~mL})$ was added to the mixture, which was extracted with diethyl ether $(3 \times 30 \mathrm{~mL})$. The combined organic extracts were washed with $\mathrm{NaHCO}_{3}(30 \mathrm{~mL}$ of a saturated aqueous solution), dried $\left(\mathrm{MgSO}_{4}\right)$, and concentrated in vacuo to leave a brown oil. Kugelrohr distillation afforded allylic alcohol 11 (6.9 g, 78\%, 100\% by GC-MS) as a clear, colorless oil; bp $80-85^{\circ} \mathrm{C} / 0.25 \mathrm{mmHg} ; R_{f}\left(20 \%\right.$ ethyl acetate in hexane) $0.34 ; \delta_{\mathrm{H}}$ $\left(300 \mathrm{MHz}, \mathrm{CDCl}_{3}\right) 5.80$ (ddt, $\left.J=16.7,10.2,6.7 \mathrm{~Hz}, 1 \mathrm{H}\right), 5.06-$ 4.85 (m, 3H), 4.24 (br, 1H), 3.96 (dd, $J=6.2,3.6 \mathrm{~Hz}, 1 \mathrm{H}), 3.77$ $(\mathrm{dd}, J=6.2,4.0 \mathrm{~Hz}, 1 \mathrm{H}), 3.59-3.55(\mathrm{~m}, 2 \mathrm{H}), 3.36(\mathrm{~s}, 3 \mathrm{H}), 2.14-$ $2.05(\mathrm{~m}, 2 \mathrm{H}), 1.87-1.64(\mathrm{~m}, 2 \mathrm{H}) ; \delta_{\mathrm{C}}\left(75 \mathrm{MHz}, \mathrm{CDCl}_{3}\right) 154.6(\mathrm{dd}$, $\left.{ }^{1} J_{\mathrm{C}-\mathrm{F}}=290.3,284.3 \mathrm{~Hz}\right), 137.7,118.2\left(\mathrm{dd},{ }^{2} J_{\mathrm{C}-\mathrm{F}}=36.4,9.8 \mathrm{~Hz}\right)$, $115.1,98.0,71.4,68.5,66.5,59.0,33.1,29.7 ; \delta_{\mathrm{F}}\left(282 \mathrm{MHz}, \mathrm{CDCl}_{3}\right)$ $-100.2\left(\mathrm{~d},{ }^{2} J_{\mathrm{F}-\mathrm{F}}=64.0 \mathrm{~Hz}, 1 \mathrm{~F}\right),-110.0\left(\mathrm{dd},{ }^{2} J_{\mathrm{F}-\mathrm{F}}=64.0 \mathrm{~Hz}\right.$, $\left.{ }^{4} J_{\mathrm{F}-\mathrm{H}}=3.8 \mathrm{~Hz}, 1 \mathrm{~F}\right) ; v_{\max }(\mathrm{film}) / \mathrm{cm}^{-1} 3475 \mathrm{~m}(\mathrm{OH}), 2932 \mathrm{~s}\left(\mathrm{CH}_{2}\right)$, $1751 \mathrm{w}\left(\mathrm{C}=\mathrm{CF}_{2}\right) ; \mathrm{m} / \mathrm{z}(\mathrm{CI}) 270\left(52 \%,\left[\mathrm{M}+\mathrm{NH}_{4}\right]^{+}\right), 215(10)$, 137 (10), $89\left(100, \mathrm{MEM}^{+}\right), 59\left(99, \mathrm{MeOCH}_{2} \mathrm{CH}_{2}{ }^{+}\right)$; HRMS (EI, $\mathrm{M}^{+}$) calcd for $\mathrm{C}_{11} \mathrm{H}_{18} \mathrm{O}_{4} \mathrm{~F}_{2}$ 252.11732, found 252.11729.

$\left(1^{\prime} R^{*}, 2 R^{*}, 4 R^{*}, 5 S^{*}\right)-5$-But-3-enyl-2,4-bis(difluoromethyl)-2-(1hydroxypent-4-enyl)-[1,3]dioxolan-4-ol (13). Trimethylsilyl chloride $(10.2 \mathrm{mmol}, 1.30 \mathrm{~mL})$ was added slowly to a solution of allyl alcohol 11 (10.0 mmol, $2.52 \mathrm{~g})$ in methanol (10 mL). The solution was stirred overnight at room temperature. The solution was concentrated in vacuo to leave a clear oil that was purified by column chromatography (gradient $10 \%$ to $50 \%$ ethyl acetate in hexane) to afford dioxolane $\mathbf{1 3}(1.35 \mathrm{~g}, 82 \%)$ as a clear, colorless oil, which crystallized at low temperature $\left(4^{\circ} \mathrm{C}\right) ; \mathrm{mp} 32-34{ }^{\circ} \mathrm{C}$; $R_{f}(20 \%$ ethyl acetate in hexane $) 0.53 ; \delta_{\mathrm{H}}\left(300 \mathrm{MHz}, \mathrm{CDCl}_{3}\right) 5.82-$ $5.64\left(\mathrm{~m}, 2 \mathrm{H}\right.$, [including $\left.\left.5.73\left(\mathrm{t},{ }^{2} J_{\mathrm{F}-\mathrm{H}}=53.7 \mathrm{~Hz}, 1 \mathrm{H}\right)\right]\right), 5.70(\mathrm{t}$, $\left.{ }^{2} J_{\mathrm{F}-\mathrm{H}}=53.7 \mathrm{~Hz}, 1 \mathrm{H}\right), 5.07-4.89(\mathrm{~m}, 4 \mathrm{H}), 4.65(\mathrm{br} \mathrm{s}, 2 \mathrm{H}), 4.28-$ $4.19(\mathrm{~m}, 1 \mathrm{H}), 3.82-3.72(\mathrm{~m}, 1 \mathrm{H}), 2.30-2.00(\mathrm{~m}, 4 \mathrm{H}), 1.83-1.50$ $(\mathrm{m}, 4 \mathrm{H}) ; \delta_{\mathrm{C}}\left(300 \mathrm{MHz}, \mathrm{CDCl}_{3}\right) 137.5,137.1,115.8,115.5,112.8$ $\left(\mathrm{t},{ }^{1} J_{\mathrm{C}-\mathrm{F}}=251.3 \mathrm{~Hz}\right), 112.6\left(\mathrm{t},{ }^{1} J_{\mathrm{C}-\mathrm{F}}=247.7 \mathrm{~Hz}\right), 107.15\left(\mathrm{t},{ }^{2} J_{\mathrm{C}-\mathrm{F}}\right.$ $=22.5 \mathrm{~Hz}), 100.2\left(\mathrm{t},{ }^{2} J_{\mathrm{C}-\mathrm{F}}=26.1 \mathrm{~Hz}\right), 81.0,70.0,29.9,29.7$, 29.4, 28.4; $\delta_{\mathrm{F}}\left(300 \mathrm{MHz}, \mathrm{CDCl}_{3}\right)-130.4\left(\mathrm{dd},{ }^{2} J_{\mathrm{F}-\mathrm{F}}=292.3 \mathrm{~Hz}\right.$, $\left.{ }^{2} J_{\mathrm{F}-\mathrm{H}}=53.7 \mathrm{~Hz}, 1 \mathrm{~F}\right),-132.8\left(\mathrm{dd},{ }^{2} J_{\mathrm{F}-\mathrm{F}}=292.3 \mathrm{~Hz},{ }^{2} J_{\mathrm{F}-\mathrm{H}}=\right.$ $53.7 \mathrm{~Hz}, 1 \mathrm{~F}),-133.7\left(\mathrm{dd},{ }^{2} J_{\mathrm{F}-\mathrm{F}}=292.3 \mathrm{~Hz},{ }^{2} J_{\mathrm{F}-\mathrm{H}}=53.7 \mathrm{~Hz}\right.$, $1 \mathrm{~F}),-135.5\left(\mathrm{dd},{ }^{2} J_{\mathrm{F}-\mathrm{F}}=292.3 \mathrm{~Hz},{ }^{2} J_{\mathrm{F}-\mathrm{H}}=53.7 \mathrm{~Hz}, 1 \mathrm{~F}\right)$; $\nu_{\max }($ neat $) / \mathrm{cm}^{-1} 3428 \mathrm{br}(\mathrm{OH}), 2931 \mathrm{~s}\left(\mathrm{CH}_{2}\right), 1642 \mathrm{~s}(\mathrm{C}=\mathrm{C}), 1073$ $\mathrm{s}(\mathrm{C}-\mathrm{F}) ; \mathrm{m} / \mathrm{z}$ (EI) $328\left(6 \%, \mathrm{M}^{+}\right), 310\left(22, \mathrm{M}-\mathrm{H}_{2} \mathrm{O}\right), 300(100$, $\mathrm{M}-\mathrm{C}_{2} \mathrm{H}_{4}$ ). Calcd for $\mathrm{C}_{14} \mathrm{H}_{20} \mathrm{O}_{4} \mathrm{~F}_{4}$ : C, 51.22; H, 6.14. Found: C, 51.34; H, 6.09.

Crystal data: $\mathrm{C}_{14} \mathrm{H}_{20} \mathrm{O}_{4} \mathrm{~F}_{4}$, crystal size $0.31 \times 0.26 \times 0.22 \mathrm{~mm}^{3}$, $M=164.15$, monoclinic, space group $P 2(1) / n$, unit cell dimensions $a=12.8189(9) \AA, b=7.7506(5) \AA, c=15.7635(11) \AA, \alpha=90^{\circ}$, $\beta=94.2810(10)^{\circ}, \gamma=90^{\circ}, V=1561.80(18) \AA^{3}, Z=4, D_{\text {calcd }}=$ $1.396 \mathrm{Mg} \mathrm{m}^{-3}, F(000)=688, \mu($ Mo K $\alpha)=0.130 \mathrm{~mm}^{-1}, T=$ $150(2) \mathrm{K}, 10838$ total reflections measured, 2748 independent $\left(R_{\mathrm{int}}\right.$ $=0.0202$ ), which were used in all calculations. Final $R$ indices

(26) For recent computational studies of enzymic enolization reactions, see: (a) Mazunder, D.; Kahn, K.; Bruice, T. C. J. Am. Chem. Soc. 2003 , 125, 7553. (b) Jogl, G.; Rozovsky, S.; McDermott, A. E.; Tong, L. Proc. Natl. Acad. Sci. U.S.A. 2003, 100, 50. (c) Feierberg, I.; Aqvist, J. Theor. Chem. Acc. 2002, 108, 71. (d) Donini, O.; Darden, T.; Kollman, P. A. J. Am. Chem. Soc. 2000, 122, 12270.

(27) Patel, S. T.; Percy, J. M.; Wilkes, R. D. Tetrahedron 1995, 51, 9201. 
(for reflections with $I>2 \sigma(I)$ ) were $R 1=0.0362, \omega R 2=0.1626$; $R$ indices (all data) were $R 1=0.0387, \omega R 2=0.0954$.

Measurement of Reaction Rates. Alcohol 11 was exchanged (OH for $\mathrm{OD}$ ) by evaporation from $\mathrm{CD}_{3} \mathrm{OD}$ several times before use for deuteriation experiments. Reactions were intiated by the addition of TMS-Cl to a $\mathrm{CD}_{3} \mathrm{OD}$ or $\mathrm{CD}_{3} \mathrm{OH}$ solution of $d-\mathbf{1 1}$ or 11, respectively, from a microsyringe in an NMR tube which was immediately capped, sealed with film, and transferred to the probe of the NMR spectrometer. (Trifluoromethoxy)benzene was used as an internal standard.

Between 60 and 240 data points were recorded for each kinetic run. Each spectrum was automatically phased and integrated. Data were transferred to spreadsheets and normalized against the internal standard. The data fitted well to first-order plots $\left(R^{2}=0.999\right.$ typically).
Acknowledgment. We thank the University of Leicester for a studentship (R.R.) and Professor A. J. Kirby FRS (University of Cambridge) for helpful discussions.

Supporting Information Available: NMR spectra $\left({ }^{1} \mathrm{H},{ }^{13} \mathrm{C},{ }^{19} \mathrm{~F}\right)$ for 11, partial ${ }^{13} \mathrm{C}$ and ${ }^{19} \mathrm{~F}$ NMR spectra during methanolysis, kinetic plots, and rate constants for methanolysis in protic and deuterated media, Cartesian coordinates, energies and atomic charges for B3LYP/6-311++ $\mathrm{G}^{* *}$ optimized structures for ground transition, and product states for $\mathbf{3}$ and $\mathbf{1 8}$. This material is available free of charge via the Internet at http://pubs.acs.org.

JO061450Y 